\title{
External penile prosthesis as a novel approach to the treatment of erectile dysfunction
}

\author{
Alex Tatem ${ }^{1}$, Jason R. Kovac ${ }^{2}$ \\ ${ }^{1}$ Department of Urology, Indiana University, Indianapolis, Indiana, USA; ${ }^{2}$ Men's Health Center, Indianapolis, Indiana, USA \\ Correspondence to: Dr. Jason R. Kovac, MD, PhD, FACS, FRCSC. Men's Health Center, 8240 Naab Road, Suite 220, Indianapolis, Indiana 46260, \\ USA. Email: jkovac@urologyin.com. \\ Comment on: Wassersug R, Wibowo E. Nonpharmacological and non-surgical strategies to promote sexual recovery for men with erectile \\ dysfunction. Transl Androl Urol 2017;6:S776-94.
}

Submitted Oct 30, 2017. Accepted for publication Nov 01, 2017.

doi: $10.21037 /$ tau.2017.11.01

View this article at: http://dx.doi.org/10.21037/tau.2017.11.01

Erectile dysfunction (ED) is a difficult issue for both patients and physicians alike. Complexities surrounding the human sexual experience, including interpersonal relationships and sexual preferences, often make evaluation complex. Physicians tend to treat patients as isolated individuals while focusing exclusively on the restoration of erectile function. However, intimacy is typically much more complex and truly a couple's issue.

Complicating factors include physicians themselves. Most tend to have an understanding of the traditional treatments for ED. Unfortunately, alternatives are rarely known or discussed. Indeed, most can be me met with ridicule and disbelief. In the associated manuscript, Wassersug and Wibowo (1) introduce several novel concepts into the treatment of ED including the use of external penile prosthetics and penile sleeves.

Many advances have been made in the treatment of ED over the years including testosterone supplementation, PDE5i therapy, intracavernosal injections and penile implants, as well as the growth of personalized penile injections. However, many patients still fail to find appropriate resolution. Furthermore, in spite of the significant advances in prosthetic urology, many patients are still unwilling, or even financially able, to undergo penile prosthetic implantation. As such, physicians in general, and ED specialists in particular, should educate themselves on novel devices that might give patients the sexual satisfaction that they are seeking.

Non-invasive, over-the-counter sexual aids outside of the standard ED treatments should be included in the armamentarium of all ED specialists. Studies on these devices are sparse-but this should not deter physicians from offering them as alternatives. Care must obviously be taken when introducing the concept. Expert knowledge of the devices available and the costs involved can prove invaluable. Indeed, something as simple as having samples available in the office can take the therapy out of the realm of "sex-shops" and sets the stage for treatment in the medical setting.

For example, as discussed by Wassersug and Wibowo (1), the terms "belted prosthetic phallus" could be used to "medicinize" the more common "sex toy" name of "strap-on dildo". Modified devices with ridges and increased sizes, along with penile vibrators and built in attachments, could also be explored. Case reports on the use of these devices (2) suggest that an external prosthesis, when incorporated in penetrative sex, may recreate the sensory experience of coital sex without the patient needing penile rigidity.

Published data regarding the use, and effectiveness of these types of external devices is lacking. It is hoped that the manuscript contained in this issue of Translational Andrology and Urology will introduce a new audience to this conceptthereby helping to increase options for the treatment of ED.

\section{Acknowledgements}

None.

\section{Footnote}

Conflicts of Interest: The authors have no conflicts of interest to declare. 


\section{References}

1. Wassersug R, Wibowo E. Nonpharmacological and nonsurgical strategies to promote sexual recovery for men with

Cite this article as: Tatem A, Kovac JR. External penile prosthesis as a novel approach to the treatment of erectile dysfunction. Transl Androl Urol 2017;6(Suppl 5):S795-S796. doi: 10.21037/tau.2017.11.01 erectile dysfunction. Transl Androl Urol 2017;6:S776-94.

2. Gray RE, Klotz LH. Restoring sexual function in prostate cancer patients: an innovative approach. Can J Urol 2004;11:2285-9. 